\title{
Formação de leitores: a dimensão afetiva na mediação da família
}

\author{
Isabela Ramalho Orlando1; https://orcid.org/0000-0001-9721-2402
}

Sérgio Antônio da Silva Leite'; https://orcid.org/0000-0003-2998-7112

\begin{abstract}
Resumo
A presente pesquisa teve por objetivo descrever e analisar o processo de constituição de leitores, com sujeitos universitários, focando os impactos afetivos das situações de mediação entre esses sujeitos e as práticas de leitura literária vivenciadas durante suas vidas, especialmente no ambiente familiar. A pesquisa foi realizada com estudantes dos anos iniciais da graduação de uma universidade pública, do interior do Estado de São Paulo. Os sujeitos eram estudantes de diferentes áreas do conhecimento, caracterizados como leitores autônomos. Entende-se por leitor autônomo aquele sujeito que lê por iniciativa própria, o que sugere que a leitura literária já representa uma atividade intrinsecamente relevante para ele. A pesquisa fundamenta-se em teorias da área da Psicologia, principalmente nas ideias de Vygotsky (1998, 2005) e de Wallon (2007, 2008). A coleta de dados foi realizada através do procedimento de Entrevistas Recorrentes, realizadas com estudantes universitários que se reconheciam como leitores autônomos. No processo de análise, os dados foram agrupados em Núcleos Temáticos, referentes aos diferentes mediadores identificados. Posteriormente, tais Núcleos foram discutidos com base na abordagem teórica assumida. Os resultados reforçam a importância da mediação e de seus impactos afetivos na constituição desses sujeitos como leitores, discutindo-se aspectos detectados nas histórias de mediações vivenciadas ao longo de suas vidas, em especial na família.
\end{abstract}

Palavras-chave: Afetividade; leitura; mediação.

\section{Readers development: the affective dimension of the family's mediation}

\begin{abstract}
The aim of the present research was to describe and analyze the readership process, with university students, focusing on the affective impacts of mediation situations among those students and the literary reading practices lived during their lives, especially in the family environment. The research was carried out with students from the initial years of graduation from a public university, in the interior of the State of São Paulo. The students were from different areas of knowledge, characterized as autonomous readers. Autonomous reader is understood as the person who reads on his own initiative, which suggests that literary reading already represents an activity intrinsically relevant to it. The research is based on theories of the area of Psychology, mainly in the ideas of Vygotsky $(1998,2005)$ and Wallon $(2007,2008)$. The data collection was performed through the Recurrent Interviews procedure, carried out with university students, who considered themselves autonomous readers. The analysis process grouped the data in Thematic Nuclei, referring to the different mediators identified. Subsequently, these nuclei were discussed based on the assumed theoretical approach. The results reinforce the importance of mediation and its affective impacts on the constitution of those students as readers, discussing aspects detected in the histories of mediations experienced throughout their lives, especially in the family.
\end{abstract}

Keywords: Affectivity; reading; mediation.

\section{Formación de lectores: la dimensión afectiva en la mediación de la familia}

\section{Resumen}

En la presente investigación se tuvo por objetivo describir y analizar el proceso de constitución de lectores, con sujetos universitarios, enfocando los impactos afectivos de las situaciones de mediación entre estos sujetos y las prácticas de lectura literaria, vivenciadas durante sus vidas, especialmente en el ambiente familiar. La investigación fue realizada con estudiantes de los cursos iniciales de la graduación de una universidad pública, del interior del Estado de São Paulo. Los sujetos eran estudiantes de distintas áreas del conocimiento, caracterizados como lectores autónomos. Se entiende por lector autónomo aquel sujeto que lee por iniciativa propia, lo que sugiere que la lectura literaria ya representa una actividad intrínsecamente relevante para él. La investigación se fundamenta en teorías del área de la Psicología, principalmente en las ideas de Vygotsky (1998, 2005) y de Wallon (2007, 2008). La recolecta de datos fue realizada a través del procedimiento de Entrevistas Recurrentes siendo que, en el proceso de análisis, esos fueron agrupados en Núcleos Temáticos, referentes a los diferentes mediadores identificados. Posteriormente, tales núcleos fueron discutidos con base en el abordaje teórico asumida. Los resultados refuerzan la importancia de la mediación y de sus impactos afectivos en la constitución de esos sujetos como lectores, discutiéndose aspectos detectados en las historias de mediaciones vivenciadas a lo largo de sus vidas, en especial en la familia.

Palabras clave: Afectividad; lectura; mediación.

1 Universidade Estadual de Campinas - Campinas - São Paulo - Brasil; isabelarorlando@gmail.com; sasleite@uol.com.br) 


\section{Introdução}

A presente pesquisa teve por objetivo descrever e analisar a dimensão afetiva nas situações de mediação entre o sujeito e as práticas de leitura literária, dando-se ênfase aos processos de mediação ocorridos no ambiente familiar. A pesquisa foi realizada com estudantes de uma universidade brasileira de diferentes áreas do conhecimento, caracterizados como leitores autônomos. Entende-se por leitor autônomo aquele sujeito que lê por iniciativa própria, o que sugere que a leitura literária já se constituiu como uma atividade intrinsecamente relevante para eles.

A pesquisa fundamentou-se em teorias da área da Psicologia, principalmente na abordagem histórico-cultural de Vygotsky $(1984 / 1998,1987 / 2008)$ e na teoria do desenvolvimento de Wallon (2002/2007, 1942/2008). Além disso, assume-se a visão dialética de leitura defendida por (Chartier, 1985/1990). O foco da pesquisa foi o ambiente familiar devido à sua importância na formação do indivíduo. Considera-se que a leitura literária é uma prática social da qual o indivíduo apropria-se a partir da interação com o "outro", sendo a mediação da família uma das possíveis condições determinantes para se estabelecer uma relação afetiva positiva entre o sujeito e a prática da leitura de textos literários. Supõe-se, portanto, que a mediação realizada pela família poderá ser um fator fundante para a constituição do indivíduo como leitor autônomo.

\section{Afetividade}

A afetividade é um conceito amplo, constituinte do processo de desenvolvimento humano, o qual, por sua vez, ocorre por meio da apropriação da cultura pelo indivíduo, principalmente através das relações interpessoais. Esse contato entre o indivíduo e os objetos e elementos culturais é sempre mediado, de modo que o seu desenvolvimento - e sua constituição como ser social se dá através das interações sociais com o os diversos elementos do seu ambiente. É com base nas ideias de Vygotsky $(1998,2008)$ e Wallon (2008) que se pressupõem os aspectos cognitivos e afetivos presentes nessas interações, fundamentais para o desenvolvimento humano.

Wallon (2008) afirma que é a partir do contato social que o indivíduo consegue se definir como "pessoa". Dessa forma, são as trocas e construções estabelecidas na interação com o "outro" que permitem ao indivíduo caracterizar-se como um sujeito único, com base na construção de um universo simbólico pessoal.

Vygotsky (1984/1998, 1987/2008), igualmente, considera que a constituição do indivíduo se dá através das interações sociais; em sua abordagem teórica, destacam-se os conceitos de mediação e internalização. Segundo esse autor, o indivíduo apropria-se dos elementos de sua cultura (valores, práticas, ideias etc.) por meio do processo de internalização de seus significados e sentidos, processo em que o sujeito reconstrói, internamente, a partir de sua ação e reflexão pessoal, aquilo que experienciou, a princípio, externamente. Desta forma, o indivíduo constitui seus sentidos e significados, construindo, assim, seu universo simbólico amplo e complexo - em outras palavras, sua subjetividade, como ensina Rey (2003).

O conceito de mediação é fundamental para a compreensão do papel da cultura no desenvolvimento humano. Vygotsky (1998) considera que o indivíduo apropria-se dos elementos da cultura através das interações sociais e que sua relação com o mundo ocorre por meio da intervenção de sistemas simbólicos, sendo que a fala desempenha um papel fundamental nesse processo, quando se interioriza e passa a constituir o pensamento verbal. Dessa forma, a internalização dos objetos e conteúdos culturais permite o desenvolvimento das funções psicológicas superiores, típicas da atividade humana, sendo, pois, um processo que se desenvolve através da mediação de agentes culturais.

Nessa perspectiva, pode-se entender que a leitura literária configura-se como uma prática social, cujos significados e sentidos poderão ser internalizados pelo sujeito a partir das interações com o "outro", o qual realiza a mediação entre o sujeito e essas práticas, desde a infância. O processo de constituição do sujeito como leitor autônomo, segundo a abordagem aqui assumida, é determinado, portanto, pela história de mediação vivenciada através das práticas de leitura e das marcas afetivas por elas impressas no sujeito, a partir das experiências vivenciadas ao longo da vida.

Wallon (2007) apresenta uma visão monista e integradora do homem, segundo a qual o desenvolvimento humano explica-se pela relação dialética entre quatro campos funcionais: afetivo, cognitivo e motor, que formam o quarto campo, a pessoa. O autor diferencia os conceitos de afetividade e de emoção: afetividade refere-se a um conjunto amplo de manifestações que envolvem emoções (origem biológica) e sentimentos (origem psicológica); desenvolve-se através da apropriação dos sistemas simbólicos culturais.

Já as emoções, que caracterizam as primeiras respostas do recém-nascido, são de natureza orgânica e correspondem a manifestações corporais de estados subjetivos. Rubor, palidez, aumento de batimentos cardíacos são exemplos dessas manifestações corporais. Além disso, as emoções têm uma função social que se refere à comunicação e mobilização do outro no período inicial da vida, através do choro e da agitação física do bebê.

Wallon (2007, 2008) considera que a afetividade exerce papel fundamental no desenvolvimento humano. Afirma ser possível entender esse processo em estágios, sendo que a afetividade está presente em todos eles, seja de maneira predominante ou não. Dessa forma, verifica-se que em todas as fases do desenvolvimento, propostas pelo autor, as funções da afetividade e da cognição estão presentes, indissociavelmente, observando-se uma alternância de predomínio entre cada uma delas.

Com base nos estudos de Vygotsky e de Wallon, pode-se inferir que o processo de desenvolvimento humano se dá a partir das interações sociais, marcadas por conteúdos afetivos e cognitivos, que se influenciam mutuamente: cada 
um desses campos alimenta-se dos progressos ocorridos no outro. Essas interações são determinantes para a natureza da relação que o indivíduo estabelecerá com os objetos e conteúdos culturais, sendo que tais relações não são apenas cognitivas, mas marcadamente afetivas, sendo que tais impactos variam em um contínuo positivo / negativo.

Nesse sentido, assume-se aqui o pressuposto básico defendido pelos estudos e pesquisas realizados pelos membros do Grupo do Afeto ${ }^{1}$, segundo o qual as relações que se estabelecem entre sujeito e objeto são também afetivas, ou seja, não se reduzem apenas à dimensão cognitiva. Portanto, tais relações provocam, no sujeito, impactos afetivos internos e subjetivos, positivos ou negativos, dependendo da qualidade da relação vivenciada. A médio e a longo prazo, histórias marcadas por relações afetivas positivas produzem movimentos de aproximação entre sujeito e objeto; o inverso também vale para se explicarem os movimentos de afastamento (Leite, 2012).

\section{Leitura}

A leitura literária é uma prática cultural que pode ser considerada fundamental para a plena inserção do indivíduo na sociedade, uma vez que the possibilita acesso aos bens culturais, aprimoramento de sua condição pessoal e de sua compreensão da realidade para nela intervir (Grotta, 2000). Portanto, no ambiente familiar, onde há grande atenção ao processo de formação do indivíduo, observam-se, frequentemente, diferentes estratégias e práticas para a constituição do indivíduo - crianças e jovens - como leitor, como já aponta Souza (2005).

O fenômeno da leitura foi, tradicionalmente, compreendido como mera decodificação e oralização da escrita. O sentido do texto era considerado algo estático e único, contido e limitado ao próprio texto, cabendo ao leitor apenas recuperá-lo. Dessa forma, a compreensão do texto era uma instância que se restringia ao autor, pois era ele quem fixava seu sentido correto. O leitor, por sua vez, era visto como um sujeito passivo, cuja atitude diante de um texto era de mera assimilação das ideias do autor (Grotta, 2000).

Superando essa visão, a leitura tem sido analisada através de várias matrizes teóricas, uma vez que se trata de fenômeno social e cultural abrangente. Neste artigo, tomamos como base a abordagem histórica, a qual busca mapear os costumes e as práticas de leitura, levando em consideração a relação do leitor com sua comunidade e seu momento histórico.

A abordagem histórica, apresentada por Chartier (1985/1990), é fundamental para compreender a relação entre sujeito e a leitura. Entende-se que esta abordagem é compatível com a concepção de sujeito como um ser histórico-cultural, a qual é adotada nessa pesquisa. O autor defende o caráter criador do ato de ler, o que garante

1 O Grupo do Afeto é parte integrante do grupo de pesquisa ALLE/ AULA (Alfabetização, Leitura e Escrita), da Faculdade de Educação/ UNICAMP. a pluralidade de leituras e sentidos. Segundo o autor, um mesmo texto é apropriado de modos diferentes, uma vez que há a intervenção criadora nos polos de recepção (no caso, os leitores).

Segundo Chartier (1997/1999), a liberdade do leitor não é absoluta, mas limitada pelas convenções e hábitos de leitura da sociedade na qual esse leitor está inserido. Convenções como os gestos, as razões de ler, os objetos, os lugares, os portadores, tudo muda conforme o contexto histórico-cultural. $\mathrm{O}$ autor considera que a multiplicidade de formas de leitura não é infinita, uma vez que as experiências individuais estão inscritas em normas e modelos compartilhados, de modo que "cada leitor, para cada leitura, é singular, mas essa singularidade é atravessada por aquilo que faz que esse leitor seja semelhante a todos aqueles que pertencem à mesma comunidade" (p.91).

Em direção semelhante, Certeau(1980/2009) assume a leitura como prática criadora e inventiva: apesar de a leitura ser uma incursão por um sistema imposto, ela não deixa de ser criativa, uma vez que os leitores utilizam-se de "táticas" para seu consumo, de forma astuciosa e inventiva.O autor afirma ainda que o texto só tem sentido graças a seus leitores, que muda com eles, em um jogo de implicações que combina uma literalidade e uma leitura (uma efetuação da obra).

Petit (2008/2009) defende que, por meio da leitura, especialmente da literatura, a interioridade humana é modificada. Segundo a autora, a leitura abre outra dimensão de espaço e tempo, própria da situação ficcional, permitindo ao sujeito tornar-se autônomo e reinventar a realidade.

Deve-se destacar, também, que os novos modos de pensar a leitura e a escrita tiveram, no Brasil, grande contribuição de Paulo Freire. Segundo o autor, o ato de ler não se esgota na decodificação do código escrito, mas é antecedido e alongado pelo conhecimento de mundo do leitor (Freire,1991, 2011).

Os trabalhos de Freire, Chartier, Petit e Certeau têm um ponto em comum: o entendimento de que leitura é produção de sentidos, pressupondo um papel ativo do sujeito no processo. Desta forma, as obras desses estudiosos permitem a percepção de que a leitura possibilita ao sujeito dialogar com as ideias do autor e, assim, revisar e aprimorar suas ideias e valores, ampliando seu universo pessoal. Pode-se supor que tais processos estão fortemente presentes no caso da leitura literária, prática focada na pesquisa aqui apresentada.

\section{Método}

A presente pesquisa apoia-se na metodologia qualitativa, na qual, segundo André e Lüdke(1986), o foco da atenção do pesquisador está no significado que as pessoas atribuem às coisas e à sua vida, produzindo, como resultado, dados fundamentalmente descritivos. Buscaram-se, intencionalmente, sujeitos que se caracterizam como leitores autônomos e que reconhecem que a família foi importante para sua constituição como leitor. Os dados foram coletados 
através do procedimento denominado Entrevistas Recorrentes (Leite \& Colombo, 2006), resultando em dados descritivos das experiências de leitura vividas pelos sujeitos no ambiente familiar. Durante o processo de análise, estes dados foram agrupados em Núcleos Temáticos (Zanelli, 1992).

\section{Seleção dos Sujeitos}

Foram intencionalmente escolhidos sujeitos que se caracterizam como leitores autônomos: leitores que leem por iniciativa própria e o fazem por considerar a leitura literária como uma atividade cultural de importância para o desenvolvimento pessoal. Optou-se por sujeitos universitários, por serem indivíduos que já viveram uma trajetória longa de contato com a leitura e, portando, teriam mais experiências a relatar.

A instituição onde foram selecionados os três sujeitos foi uma universidade pública brasileira. Concretamente, a busca ocorreu por meio da internet, por contatos pessoais e através de listas fornecidas por alguns cursos da referida universidade. Houve uma fase de pré-escolha, baseada nos dados iniciais fornecidos pelos alunos, seguida pela escolha a partir de uma entrevista inicial. A opção por trabalhar com poucos sujeitos justifica-se pelo propósito da pesquisa de resgatar as experiências de mediação entre sujeitos e as práticas de leitura, ao longo de suas vidas, de forma que um número menor de sujeitos possibilitaria maior aprofundamento nos relatos de cada um deles, semelhante ao que ocorre nos procedimentos de estudos de caso.

\section{Caracterização dos sujeitos}

O Sujeito 1, do sexo masculino, passou sua infância e adolescência em São José dos Campos (SP), onde morava com os pais e a irmã. Seu pai tem formação completa no Ensino Superior e a mãe cursou até o Ensino Médio. No momento das entrevistas, o sujeito cursava o $3^{\circ}$ semestre de um curso básico da área de Exatas. Demonstra grande entusiasmo pela leitura e fala com propriedade sobre os autores e livros de que gosta, resultado do hábito de sempre pesquisar sobre literatura.

A cidade natal do Sujeito 2, do sexo feminino, é Franca (SP), onde morava com os pais. A mãe e o pai têm curso superior completo e ambos trabalham como funcionários públicos. Quando as entrevistas foram realizadas, ela cursava o $3^{\circ}$ semestre de Letras. Conta que, durante o curso, descobriu um novo gosto além da literatura: a linguística, área em que pretende realizar atividades de iniciação científica.

O Sujeito 3 é natural de São Paulo (SP), do sexo feminino; viveu com seus pais até iniciar a graduação. Os pais têm curso superior completo. Quando a pesquisa foi realizada, o sujeito cursava o $1^{\circ}$ semestre do curso de Medicina. Atualmente, procura conciliar o tempo de estudos com a leitura, mas relata ter dificuldade para encontrar um local tranquilo para ler.

\section{Procedimentos de coleta de dados}

As entrevistas individuais eram agendadas com os sujeitos, sendo realizadas em local e horário que atendessem as necessidades de cada um. A primeira entrevista era iniciada por uma questão central, sobre os mediadores que possibilitaram a constituição do sujeito como leitor literário, desde a fase inicial da infância. A segunda entrevista era iniciada com a apresentação dos Núcleos Temáticos organizados a partir dos dados da entrevista anterior. Foi solicitado que o sujeito avaliasse e comentasse os núcleos organizados e novas questões eram apresentadas sobre o papel dos agentes mediadores, visando aprofundar sua importância no processo. Com cada sujeito foram realizadas duas entrevistas, todas gravadas mediante permissão dos entrevistados. ${ }^{2}$

\section{Resultados}

A organização de Núcleos Temáticos consiste na identificação de trechos da transcrição das entrevistas que representam os objetivos buscados na pesquisa e no agrupamento desses trechos de acordo com sua natureza e função. Nesta pesquisa, os Núcleos Temáticos indicam os aspectos relacionados às dimensões afetivas identificadas nas experiências de leitura literária relatadas pelos sujeitos, com ênfase no ambiente familiar.

A composição dos Núcleos Temáticos ocorreu, portanto, a partir da organização das falas de cada sujeito. Os respectivos núcleos foram organizados em matrizes, materializadas em quadros impressos, as quais foram discutidas com cada um deles separadamente, nas entrevistas que se seguiram ao longo do processo de coleta de dados. Ao se encerrarem as entrevistas com os três sujeitos, as falas estavam organizadas em três conjuntos de matrizes individuais. A etapa final da organização desses dados, realizada exclusivamente pelos pesquisadores, foi a construção de uma matriz única, a partir das matrizes com as falas dos três sujeitos, respectivamente. Essa matriz final aborda os seguintes Núcleos Temáticos, comuns no processo de constituição de leitor dos três sujeitos: Vivências de leitura; Práticas de leitura na escola; Papel da Família; Papel dos Amigos; O Namorado; Acesso aos livros; O impacto da leitura.

Serão destacados os pontos mais relevantes desses núcleos, referentes aos diferentes mediadores, dando-se ênfase ao papel da família no processo de constituição dos sujeitos como leitores de textos literários.

\section{Mediação da família}

Os relatos dos três sujeitos mostram que os familiares foram mediadores de grande impacto. A contação de histórias na infância, geralmente realizada pela mãe ou pelo pai, é carregada de marcas afetivas positivas e são as primeiras lembranças dos sujeitos em relação à leitura. A figura dos

2 A pesquisa foi aprovada pela comissão de Ética em Pesquisa, sob CAAE 21344713.0.0000.5404 
avós também aparece como fonte de admiração, de modo que os avós leitores foram um estímulo para que os sujeitos buscassem maior envolvimento com a leitura, como se pode observar no relato do Sujeito 1:"Cresci vendo isso da parte do meu avô. Mesmo sem escolaridade, ele adquiriu conhecimento ao procurar livros de história e também assuntos relacionados à ciência."

Os tios, tias e madrinhas influenciaram os sujeitos em uma fase posterior, quando já deixavam a infância e buscavam leituras mais complexas. Esses familiares recomendavam livros aos sujeitos, além de estarem dispostos a discutir o material lido com eles, o que, na opinião deste, enriquecia a experiência de leitura: "A gente começou a ter essa troca de informações, começou a emprestar livros uma pra outra. Foi muito bom!" (Sujeito 2).

O Sujeito 1 era o único que tinha uma irmã, mais nova. Ele conta que se sentia responsável pela formação dela como leitora, de modo que passou a ler os livros de que ela gostava para poder estimulá-la a ler mais. Um dos relatos é sobre uma coleção de livros que os dois fizeram juntos:

Ela começou a ler a série Percy Jackson. Leu os dois primeiros e parou. Um dia, eu estava de férias e pensei em ler o mesmo que minha irmã estava lendo. Gostei bastante do livro, e dei a ideia de completarmos a coleção juntos. (Sujeito 1)

Os sujeitos relatam que, ao longo de suas vidas, tiveram suporte dos familiares que garantiu o acesso aos livros. Esse suporte se deu de diversas formas: empréstimo de livros de coleções particulares; compra de livros e gibis, muitas vezes em sebos, por terem preços mais acessíveis; visitas a feiras de livros. Eles ressaltam que, desde a infância, tinham acesso aos livros que havia em suas casas, além de permissão para manuseá-los e lê-los. Essa facilidade foi, do ponto de vista dos sujeitos, determinante para que estabelecessem vínculos positivos com esse material.

A prática de frequentar a biblioteca também é lembrada pelos sujeitos 1 e 2 . Eles contam que, especialmente na infância, a biblioteca municipal de suas cidades foi uma rica fonte de materiais de leitura. Esses relatos carregam marcas afetivas em diversos aspectos: os sujeitos recordam-se com carinho desses momentos como sendo um passeio em família, além de demonstrarem afeição pelas bibliotecas em si, destacando características da arquitetura do prédio e das bibliotecárias.

\section{Outros mediadores identificados}

As práticas de leitura na escola tiveram diferentes impactos ao longo da vida dos sujeitos: muitas vezes o material lido era considerado desinteressante pelos sujeitos ou eles desmotivavam-se em razão das atividades avaliativas propostas. Outras vezes, especialmente durante o Ensino Fundamental I, as experiências foram mais proveitosas e os livros eram mais instigantes. Os três sujeitos ressaltam que, mesmo quando as práticas de leitura na escola não Ihes agradavam, eles continuavam vivenciando atividades prazerosas no ambiente familiar. Houve, ao longo da vida escolar dos sujeitos, um professor de literatura que proporcionou atividades prazerosas com a leitura.

Além disto, pode-se observar, nos três relatos, a influência que o professor de literatura do Ensino Médio exerceu na constituição dos sujeitos como leitores autônomos. Eles destacam que essa era uma fase de transição - da adolescência para a vida adulta, da escola para universidade - e isso se refletiu também no amadurecimento da leitura realizada por eles. Seus professores de literatura foram responsáveis por guiar essa transição e orientar os sujeitos, por exemplo, na leitura dos clássicos:

Machado eu li quando a gente estudou Realismo. Eu não gostava tanto, mas gostei muito do Dom Casmurro só porque ela fez um estudo do livro com a gente. Ela era sensacional! Ela falava muito, ela explicava muito bem! E aí fazia muito sentido! (Sujeito 3)

Os relatos demonstram que as exposições feitas pelos professores, acerca dos autores e suas obras, foi fundamental para que pudessem apreciar a leitura desses clássicos.

\section{Discussão}

Esta pesquisa buscou investigar o processo de constituição do leitor literário, destacando o papel da família nesse processo e tendo como base os estudos acerca do desenvolvimento humano de Wallon e Vygotsky. Entende-se que esse processo é socialmente construído e que a família pode ter papel importante. Além disso, o processo de formação do leitor autônomo - aquele que lê por iniciativa própria - é marcado por uma história de mediação com impactos afetivamente positivos, sendo que os dados desta pesquisa suportam tal interpretação teórica.

Cada um dos participantes da pesquisa trouxe uma história singular de envolvimento com a leitura. No entanto, foi possível agrupar aspectos comuns do processo de formação de leitor desses sujeitos, especialmente sobre a mediação realizada pelos familiares, e, dessa maneira, foi possível elaborar considerações sobre a importância dos conteúdos afetivos das mediações vivenciadas pelo sujeito para sua constituição como leitor autônomo.

Para se compreender a formação do leitor, é indispensável a análise das situações de mediação entre o indivíduo e os materiais escritos, identificadas na sua história passada e presente, de modo que, no plano microgenético, cabe à pesquisa identificar as singularidades deste processo e elucidar como ele ocorre nas histórias individuais. Os dados desta pesquisa permitem inferir que esses sujeitos se tornaram leitores a partir das interações com o "outro" em situações diversas, como na escola, na biblioteca e, principalmente, no ambiente familiar. 
Wallon $(2007,2008)$ afirma que todas as interações são carregadas de conteúdos afetivos. Sendo a leitura literária um objeto cultural apropriado pelo sujeito por meio das interações sociais, assume-se que a qualidade da mediação oferecida ao sujeito possibilitou imprimir um forte valor afetivo positivo na relação de cada um deles com esse objeto. 0 movimento de aproximação desses sujeitos com as práticas sociais de leitura foi, certamente, determinado por esses conteúdos afetivos positivos, presentes em cada mediação descrita por eles. Isso pode ser observado nas falas dos sujeitos, quando contam sobre a preocupação dos pais em buscarem materiais de leitura que poderiam interessar aos filhos.

Os três sujeitos referem-se às experiências que vivenciaram, nos momentos de leitura relatados, indicando os impactos afetivos presentes na mediação por eles vivenciada. Especialmente durante a infância, eles falam sobre a atenção e o carinho dedicado pelos pais nas situações de mediação da leitura. Têm-se os exemplos das idas à biblioteca e os momentos em que os membros da família se reuniam para ler, situações em que o estar em família produz marcas afetivas positivas para as práticas de leitura.

Abramovich (1997) destaca o papel da contação de histórias na formação do leitor. A autora ressalta que é importante que a criança ouça muitas histórias para que se familiarize com o universo da leitura. Essa atividade aparece nos relatos dos sujeitos 2 e 3 e, conforme eles descrevem, acontecia à noite, antes de dormirem. O ambiente aconchegante e o momento de proximidade com os pais, durante a contação de história, imprimiu marcas afetivas positivas nos sujeitos, lembradas e citadas com emoção durante as entrevistas para coleta dos dados.

O relato do Sujeito 3 sugere que, muitas vezes, o conteúdo dos livros lidos foi esquecido, de forma que o relato centra-se na descrição da atividade compartilhada com a mãe. Souza (2005) afirma que o fato de o leitor não lembrar o conteúdo das leituras, mas recordar detalhes das cenas de leitura, indica que a interação com a figura do mediador foi o aspecto mais marcante dessa situação.

A afetividade desenvolve-se ao longo da vida, sendo que esse processo está relacionado às conquistas no plano cognitivo; ao mesmo tempo, o desenvolvimento cognitivo depende dos vínculos afetivos. A aquisição de novas estratégias de comunicação permite formas mais complexas de manifestações afetivas, como o diálogo, o respeito e a atenção. As formas de mediação da mãe do Sujeito 3 e de demonstração de afeto modificaram-se conforme o sujeito se desenvolvia. Ou seja, as manifestações afetivas tornaram-se mais complexas à medida que o sujeito apresentava conquistas no plano cognitivo. A contação de história, feita exclusivamente pela mãe, cuja principal marca afetiva é o contato físico, é substituída pelo diálogo e pela troca de opiniões.

No mesmo sentido, o Sujeito 1 relata que, com seu pai, mais do que aprender a apreciar a leitura, aprendeu a valorizar os livros. O Sujeito 2 também relata que sempre via seu pai lendo e que observava seu hábito de procurar artigos na internet e imprimi-los para ler. Ela afirma que, por ter observado essa atividade de leitura de seu pai, ela mesma desenvolveu o hábito de buscar artigos on-line. Nesse mesmo sentido, a pesquisa de Souza (2005) demonstrou que a observação de práticas de leitura realizadas pelos pais foi, para os seus sujeitos, um fator mais importante do que a mera existência de livros no ambiente familiar.

Vygotsky (1998) destaca que, através da imitação, as crianças podem executar ações que estão além de suas capacidades, de modo que imitar configura-se como parte importante do processo de desenvolvimento do sujeito. Portanto, mesmo ações que não eram dirigidas aos sujeitos, como a rotina e hábitos de leitura dos pais, influenciaram, ainda que de forma indireta, na relação que os sujeitos estabeleceram com a leitura literária.

Além de motivarem os filhos a lerem, por meio de seus hábitos individuais de leitura, as mães e os pais desses sujeitos também desenvolveram, intencionalmente, ações para favorecer o contato deles com a leitura, tais como a compra de livros, as discussões sobre leitura e as visitas a feiras de livros e bibliotecas. Esse esforço dos pais não só é identificado e reconhecido pelos sujeitos, mas também lembrado de maneira afetivamente positiva. Os três participantes da pesquisa afirmam que nunca Ihes faltaram livros, já que os pais, por meio de diferentes estratégias, garantiram o acesso aos materiais de leitura.

Outro aspecto marcante destas narrativas é que não apenas os pais foram exemplos ou incentivadores da leitura para os sujeitos, mas eles viveram cercados de familiares com quem podiam discutir sobre suas leituras, trocar livros e recomendações. O Sujeito 1 demonstra grande admiração por seu avô paterno, pelo fato de ele ter acumulado conhecimento através de suas leituras. O Sujeito 3 fala sobre suas duas avós, que a influenciaram de diferentes maneiras.

Flores (1994) afirma que os avós são responsáveis por grande parte dos valores transmitidos na família. Grotta (2000) e Souza (2005) também destacaram a influência dos avós nesse processo. As autoras relatam que a relação afetuosa com os avós leitores e admiração a eles dirigida são fatores que contribuem para aproximação do sujeito com a leitura.

Nessa direção, o Sujeito 2 enfatiza a relação com uma de suas tias, com quem conversava sobre suas leituras e trocava recomendações de livros. O gosto comum pela leitura e o hábito de discutir sobre literatura tornou a relação das duas mais próximas. Além disso, comenta que as conversas com a tia modificaram-se à medida que suas próprias leituras tornavam-se mais complexas.

Segundo Wallon (2002/2007), no desenvolvimento humano, cognição e afetividade são complementares. O relato descrito no parágrafo anterior exemplifica essa complementaridade entre cognição e afetividade. A troca de informação e a busca por novos conhecimentos através da discussão literária ocasionou a aproximação afetiva entre o sujeito e sua tia e, uma vez estabelecida esta relação, afetuosamente positiva, o interesse pela aquisição de conhecimento e pela leitura literária intensificou-se.

A figura do irmão, apontada por Flores (1994), como uma evidente influência na personalidade da criança, apa- 
rece no relato do Sujeito 1. Esse era o único entre os entrevistados que não era filho único, tendo uma irmã mais nova. O sujeito descreve uma relação próxima com a irmã e conta que se preocupava em cultivar nela o gosto pela leitura.

O processo pelo qual o sujeito se constitui como leitor autônomo pode ser melhor compreendido com auxílio do conceito de Zona de Desenvolvimento Proximal (ZDP), elaborado por Vygotsky (1984/1998). A ZDP consiste nas atividades que o sujeito realiza com auxílio de outros, por meio de uma explicação, imitação ou colaboração. É na ZDP que a mediação atua, proporcionando o desenvolvimento, que não é de caráter apenas cognitivo, mas também afetivo.

Enquanto a leitura ainda é situação emergente, a mediação é necessária para que o sujeito estabeleça vínculos afetivos com essa prática cultural. À medida que a leitura vai se tornando autônoma, a necessidade de mediadores diminui, uma vez que a própria atividade se torna intrinsecamente afetiva. Os sujeitos dessa pesquisa viveram situações de mediação com a leitura literária, ao longo de suas vidas, que foram carregadas de conteúdos afetivos positivos. Dessa forma, os sentidos por eles atribuídos à leitura literária, construídos a partir de suas experiências individuais, são também afetivamente positivos, possibilitando que essa prática se tornasse intrinsecamente afetiva e os sujeitos, por sua vez, se constituíssem como leitores autônomos. Eles afirmam que a leitura literária é uma atividade prazerosa, que a alegria sentida ao ler um livro já os estimula a ler mais. Buscam na leitura satisfação pessoal, informação e distração.

\section{Considerações Finais}

Compreende-se que os sentidos atribuídos pelos sujeitos desta pesquisa à leitura literária são resultado da qualidade das interações e de suas experiências concretas, vivenciadas durante toda a sua formação.

No ambiente familiar, os sujeitos iniciaram seu contato não só com aprática da leitura, mas também com a leitura do mundo. Assim, durante a infância, os familiares foram os principais responsáveis por mediar o contato entre o sujeito e a cultura e foi nesse período que os sujeitos vivenciaram suas primeiras experiências de leitura, as quais imprimiram fortes impactos afetivos nas relações que se estabeleceram entre eles e esta prática cultural.

Ao se considerar que a relação do sujeito com o mundo é sempre mediada, compreende-se que a qualidade afetiva das mediações experienciadas pelos sujeitos foi determinante para a relação que esses estabeleceram com a leitura. Reafirma-se, assim, o pressuposto teórico, defendido pelo Grupo do Afeto, segundo o qual o sujeito constitui-se como leitor a partir das experiências de leitura que vivencia e dos impactos afetivos por elas produzidos. Os conteúdos afetivos dessas experiências, tais como proximidade física, carinho, atenção, prazer e respeito, são internalizados e associados à prática da leitura. Nota-se que, nos relatos desses três sujeitos, respeitando-se a singularidade de cada indivíduo, as práticas de leitura vividas no ambiente familiar produziram marcas afetivas intensas e positivas. Ressalte-se, também, que os dados reforçam pesquisas anteriores no sentido de apontar a importância não só da existência de livros no ambiente familiar, mas de um "ambiente literário", centrado nas práticas de leitura dos pais que se constituem como modelos efetivos para os seus filhos.

Compreende-se que esta pesquisa traz contribuições para o entendimento do fenômeno da constituição do leitor, especialmente por enfocar a dimensão afetiva do processo, corroborando com outros autores que estudaram o tema. Em síntese, defende-se que a constituição do sujeito como leitor é um processo socialmente construído, determinado pela história concreta de mediações vivenciadas por ele, nos diversos ambientes, onde se desataca o da família, que pode representar uma instância de enorme poder formativo (Leite, 2011). Assim, o olhar sobre o ambiente familiar mostra-se relevante, uma vez que, nele, os indivíduos podem vivenciar importantes relações sociais que possibilitarão o estabelecimento de vínculos afetivos positivos com práticas sociais, fundamentais para a sua inserção cultural e formação individual, como é o caso da leitura literária.

Novos estudos devem ser realizados, buscando-se detalhar os processos de mediação vivenciados por leitores autônomos, não só na família, mas nas demais instâncias sociais. Certamente, o acúmulo de dados sobre esse processo possibilitará o encaminhamento de futuras políticas públicas, por parte dos órgãos públicos, visando à formação do cidadão leitor.

\section{Referências}

Abramovich, F. (1997). Literatura infantil: gostosuras e bobices. São Paulo: Scipione.

André, M. E. A.; Lüdke, M. (1986). Pesquisa em educação: abordagens qualitativas. São Paulo: E.P.U.

Certeau, M. (2009). A invenção do cotidiano: 1: artes de fazer. Petrópolis, RJ: vozes. (Trabalho original publicado em 1980).

Chartier, R. (1990). A história cultural: entre práticas e representações. Lisboa: Difel. (Trabalho original publicado em 1985).

Chartier, R. (1999). A aventura do livro: do leitor ao navegador. São Paulo: Fundação editora da Unesp. (Trabalho original publicado em 1997).

Flores, J. V. (1994). Influência da família na personalidade da criança. Porto: Porto.

Freire, P, (1991). Pedagogia do oprimido. Rio de Janeiro: Paz e Terra. (Trabalho original publicado em 1970).

Freire, P. (2011). Pedagogia da autonomia: saberes necessários à prática educativa. São Paulo: Paz e Terra. 
Grotta, E. C. B. (2000). Processo de formação do leitor: relato e analise de quatro histórias de vida. Dissertação de mestradoUniversidade Estadual de Campinas, Campinas-SP.

Leite, S. A. S.; Colombo, F. A. (2006). Pesquisa em educação alternativas investigativas com objetos complexos. In: Pimenta, S. G.; Ghedin, E.; Franco M. A. S. (Orgs), A voz do sujeito como fonte primária na pesquisa qualitativa: a autoscopia e as entrevistas recorrentes (pp. 117-136). São Paulo: Edições Loyola.

Leite, S. A. S. (2011). A afetividade no processo de constituição do leitor. Atos de pesquisa em educação, 6(1),25-52.

Leite, S. A. S. (2012). Afetividade nas práticas pedagógicas. Temas em psicologia, 20(2), 355-368.

Petit, M. (2009). A arte de ler ou como resistir à adversidade. São Paulo: Editora 34. (Trabalho original publicado em 2008).

Rey, F. G. (2003). Sujeito e subjetividade. São Paulo: Pioneira Thomson Learning.
Souza, J. S. Z. (2005). Mediação da família na constituição do leitor. Trabalho de conclusão de curso, Universidade Estadual de Campinas, Campinas-SP.

Vygotsky, L. S. (1998). A formação social da mente. São Paulo: Martins Fontes. (Trabalho original publicado em 1984).

Vygotsky, L. S. (2008). Pensamento e linguagem. São Paulo: Martins Fontes. (Trabalho original publicado em 1987)

Wallon, H. (2007). A evolução psicológica da criança. São Paulo: Martins Fontes. (Trabalho original publicado em 1941).

Wallon, H. (2008). Do acto ao pensamento. Rio de Janeiro: Editora Vozes. (Trabalho original publicado em 1942).

Zanelli, J. C. (1992). Formação profissional e atividades de trabalho: análise das necessidades identificadas por psicólogos organizacionais. Tese de doutorado, Universidade Estadual de Campinas, Campinas-SP. unrestricted use, distribution and reproduction in any medium, provided the original article is properly cited. 